\title{
Explaining the Financial Instability Hypothesis with Endogenous Investment: A Nonlinear Model Predictive Control Approach
}

\author{
Terence Tai-Leung Chong1,2, Richard J. Cebula ${ }^{3}$, Fangping Peng ${ }^{4}$, Maggie Foley ${ }^{3}$ \\ ${ }^{1}$ Department of Economics, The Chinese University of Hong Kong, Hong Kong \\ ${ }^{2}$ Department of International Economics and Trade, Nanjing University, Nanjing, China \\ ${ }^{3}$ Davis College of Business, Jacksonville University, Jacksonville, Florida, USA \\ ${ }^{4}$ Business School, Sun Yat-sen University, Guangzhou, China \\ Email: ${ }^{*}$ pengfp@mail.sysu.edu.cn
}

Received 25 January 2015; accepted 27 March 2015; published 30 March 2015

Copyright (C) 2015 by authors and Scientific Research Publishing Inc.

This work is licensed under the Creative Commons Attribution International License (CC BY).

http://creativecommons.org/licenses/by/4.0/

(c) (i) Open Access

\begin{abstract}
This study reveals endogenous instability in the financial market based on the dynamic interaction between endogenous investment behavior and debt in a nonlinear framework, by using a nonlinear model predictive control (NMPC) approach. It is found that when the debt ratio is below a critical threshold, increased debt has a positive effect on investment. On the other hand, when the debt ratio is above that threshold, growing financial stress and greater debt become a drag on investment, leading to an economic downturn and an outbreak of financial crisis. The paper provides theoretical support for Minsky's financial instability hypothesis.
\end{abstract}

Keywords

Minsky Cycles, Financial Instability Hypothesis, Investment

\section{Introduction}

The traditional Keynesian macroeconomic theory considers the financial sector only as the intermediary for investment and cannot fully explain economic instability induced by a complex financial system [1]. [2] examines the relationship between the financial sector and the real sector and proposes the "financial instability hypothe-

"Corresponding author.

How to cite this paper: Chong, T.T.-L., Cebula, R.J., Peng, F.P. and Foley, M. (2015) Explaining the Financial Instability Hypothesis with Endogenous Investment: A Nonlinear Model Predictive Control Approach. Journal of Mathematical Finance, 5, 83-87. http://dx.doi.org/10.4236/jmf.2015.52008 
sis”. However, the multiplier-accelerator model developed by [2] is only a linear model and is not as successful as might be expected in modeling the financial instability hypothesis [3].

[4] develops a new model for Minsky's financial instability hypothesis. However, his model does not have a micro-foundation to permit consideration of individual optimizing behavior. The groundbreaking study of [5] establishes a financial accelerator model that connects the financial sector and the real sector by using a dynamic stochastic general equilibrium (DSGE) method. Their study reveals that the financial sector has an amplification effect on the level of economic output. However, as emphasized by [6], a theoretical analysis based on traditional log-linearization techniques is likely to be inadequate due to local instability and a non-linear amplification mechanism, which neither departs from nor reverts to the steady state. Moreover, it does not track debt and investment dynamics.

A vast literature on the relationship between the financial sector and the real sector has emerged since the 2007-09 global economic recession. Much of the recent research emphasizes the role of asset prices and assetvolatility in downward destabilization, such as [7]-[9] and [10]. These studies argue that large changes in assetprice movements trigger an endogenously generated jump in risk. In contrast to the above studies, [6] and [11] focus on movements in risk premia and credit spreads, arguing that triggering of downward instability also depends on the constraints imposed on the growth of capital assets through borrowing and leveraging.

While the financial instability hypothesis puts investment in a core position, the aforementioned studies take investment as an exogenous control variable, which leads to the intractability of investment dynamics. Since investment accounts for a large proportion of national income in China, it is important to track the dynamic evolutionary path of investment. In this paper, to capture the dynamics between investment and debt, we extend the models of [6] and [7] by incorporating investment as one of the state variables. Moreover, a nonlinear model predictive control approach (NMPC) is employed to solve our model and to provide support for Minsky's financial instability hypothesis.

\section{The Model}

Our model is mostly related to [6] and [11]. However, in contrast to [6] and [11], who use consumption and investment as separate decision variables, we only use consumption as the decision variable and investment as one of the state variables, thereby making investment endogenously determined. Our model is defined as follows:

$$
V(K, B, I)=\max _{C_{t}} \int_{0}^{T} \mathrm{e}^{-r T} U\left(C_{t}\right) \mathrm{d} t
$$

subject to:

$$
\begin{gathered}
\mathrm{d} K_{t}=\left(I_{t}-\delta K_{t}\right) \mathrm{d} t \\
\mathrm{~d} B_{t}=\left(r_{t} B_{t}-\left(Y_{t}-C_{t}-I_{t}-\varphi\left(I_{t}\right)\right)\right) \mathrm{d} t \\
r_{t}=r_{0}+\beta \arctan \left(B_{t} / K_{t}\right) \\
I_{t}=k\left(\pi_{t-1}\right) Y_{t} \\
Y=K_{t}^{\alpha}
\end{gathered}
$$

where $K_{t}$ is the capital stock, $I_{t}$ the aggregate investment, $\delta$ the depreciation rate of capital, $r_{t}$ the real interest rate, $r_{0}$ the risk-free rate, $B_{t}$ the economy's aggregate debt (private and public), and $Y_{t}$ the total output. Equation (1) assumes that a social planner chooses the level of consumption $C_{t}$ to maximize inter-temporal utility (see [12] for details). We define the utility function as $U\left(C_{t}\right)=\ln C_{t}$. Equation (2) describes the changes in the capital stock in the economy. Equation (3) illustrates the evolution of aggregate debt, where $\varphi\left(I_{t}\right)$ represents the investment adjustment costs (see [11]). Equation (4) explains the decision-making behavior involving real interest rates. According to [11] and [6], real interest rates tend to reflect the level of financial stress in the economy, since the rise in leverage by individuals raises the risk premium on lending. Thus, the interest rate should be positively related to the leverage level in the economy. In our model, the lower bound for the interest rate is the risk-free rate, while the upper bound is defined by the arctan function with $\beta>0$ (see [6] for details). Equation (5) describes investment dynamics. According to [3] and [13], the investment rate is a nonlinear exponential 
function of the debt and (expected) net profit rate, $\pi_{t-1}$ according to adaptive expectation. Following [14], $\pi_{t-1}$ is defined as:

$$
\pi_{t-1}=\left(K_{t-1}^{\alpha}-I_{t-1}-\varphi\left(I_{t-1}\right)-r_{t-1} B_{t-1}\right) / K_{t-1}
$$

In order to determine the rate of investment, following [3] and [10], we define $k\left(\pi_{t-1}\right)$ as follows:

$$
k\left(\pi_{t-1}\right)=\left[\mathrm{e}^{-\lambda\left(B_{t-1} / K_{t-1}-\omega\right)^{2}}+1 /\left(1+\mathrm{e}^{-\gamma\left(\pi_{t-1}-0.05\right)}\right)\right] / 2
$$

Equation (8) indicates the investment ratio in terms of output as being dependent on profits and debt. It allows the rate of investment to be endogenously determined which is consistent with the financial instability hypothesis. The production function is provided in Equation (6).

The above system is conventionally solved by a dynamic programming (DP) approach. However, DP is subject to the curse of dimensionality since the computation time increases exponentially with the dimension of the state variables. A remedy to this problem is to use the nonlinear model predictive control (NMPC), which is an attractive alternative to the DP approach, because it only computes single (approximate) optimal trajectories and not the optimal value function for all possible initial states ([15]). Following [6] and [11], we assume $K(0)=0.9$, $B(0)=0.9, I(0)=0.4$ for the three initial conditions and $\delta=0.07, r_{0}=0.02, \beta=0.1, \gamma=1.5, \alpha=0.6$, $\omega=0.8, \lambda=1$ for the seven parameters.

Figure 1 shows the NMPC solution paths for capital, debt, and investment over time. Figure 2 plots the debtto-capital ratio against capital, with the debt-to-capital ratio on the vertical axis and the capital stock on the horizontal axis, and Figure 3 plots investment against the debt-to-capital ratio, with investment on the vertical axis and the debt-to-capital ratio on the horizontal axis.

As shown in Figure 1 and Figure 2, the debt rises rapidly over time. Yet, with an increasing risk resulting from increasing leverage, the capital stock and investment stop rising and begins to contract, and the leverage ratio then increases further. Figure 3 further explains a contraction of the investment, which happens when the leverage ratio passes a certain threshold, and additional increases in the real interest rate on debt further elevate the interest payments to an amount larger than the surplus generated to repay such debt. The economy and the investment level are initially debt-led when the debt ratio and the corresponding credit cost are low, but are likely to be dynamically unstable and debt-burdened once the leverage ratio passes the threshold. This is because the increasing leveraging risk premia and falling (or negative) capital gains would lead to unsustainable debt repayments. These findings support Minsky’s financial instability hypothesis.

\section{Conclusion}

Endogenously unstable financial markets have attracted much attention since the outbreak of the global financial crisis in 2007. To better model the dynamic mechanism of the financial instability hypothesis initially put forth by [2], we have developed a theoretical model describing the dynamics of the financial instability when the

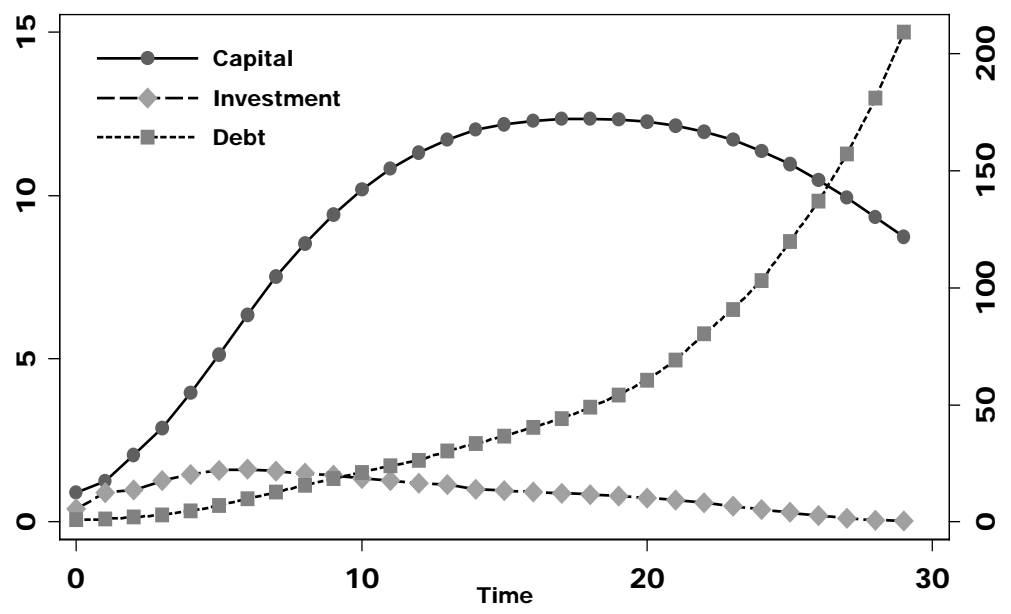

Figure 1. The capital, debt, and investment dynamics over time. 


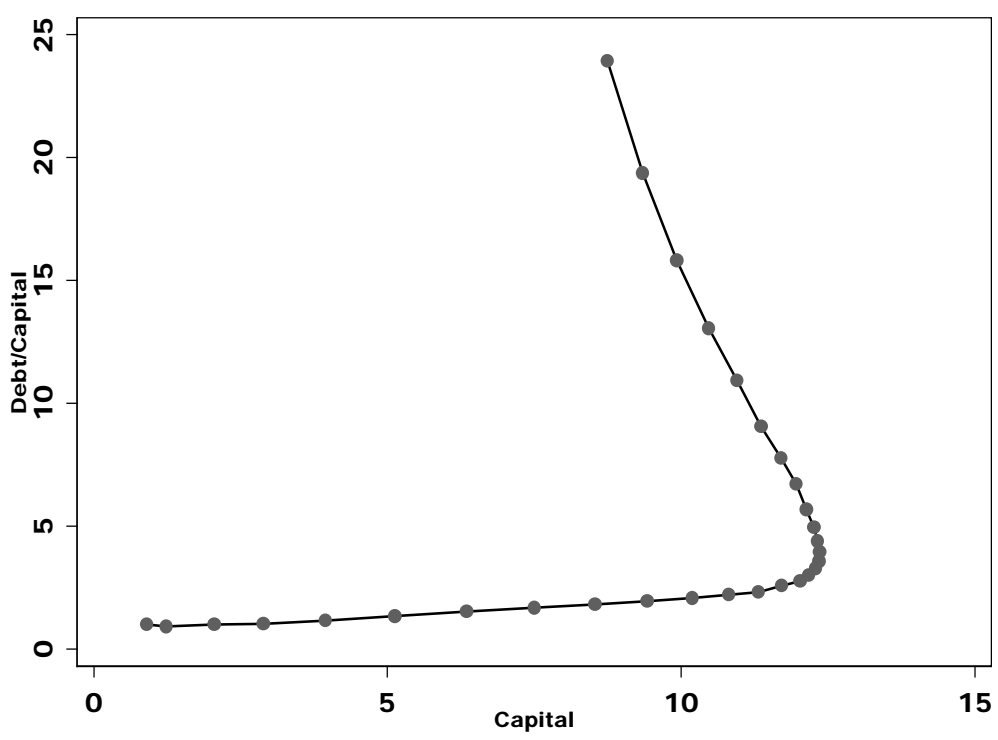

Figure 2. The debt dynamics against the capital.

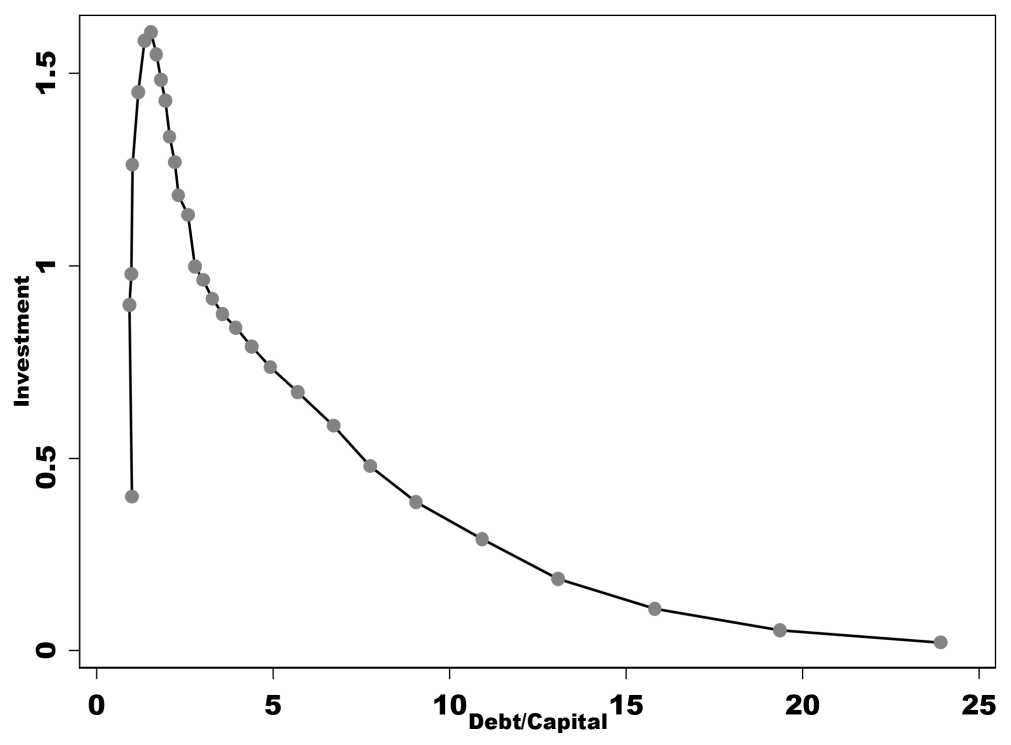

Figure 3. The investment dynamics against the debt.

economy is being exposed to shocks in credit spread. In particular, our model incorporates investment as one of endogenous constraints. By using a nonlinear model predictive control approach, we have examined how financial instability is created endogenously. The model established in this paper can be used to capture the core of the financial instability hypothesis and demonstrate financial endogenous instability. Our theoretical model implies that unfavorable credit spreads and high leverage ratios play an important role for the recession of the investment and financial instability. In the presence of large credit spreads and high leveraging, increasing leveraging can induce instabilities and the meltdown of investment. In terms of policy implications, our results strongly suggest that excessive leverage is one of the important reasons leading to declining investment at present in China, and so deleveraging can be currently a wise strategy in China. For future research, one may conduct empirical test to verify the theory developed in this paper.

\section{Acknowledgements}

We would like to thank Cong Qin, Mandy Cheung and Junjie Guo for able research assistant. The financial 
support from the National Natural Science Foundation of China (71201174), the Natural Science Foundation of Guangdong Province, China (S2013010015019) and Fundamental Research Funds for the Central Universities (1209022) are gratefully acknowledged.

\section{References}

[1] Minsky, H.P. and Kaufman, H. (2008) Stabilizing an Unstable Economy. McGraw-Hill, New York.

[2] Minsky, H.P. (1957) Monetary Systems and Accelerator Models. American Economic Review, 67, 860-883.

[3] Keen, S. (2000) The Nonlinear Economics of Debt Deflation. In Commerce, Complexity, and Evolution: Topics in Economics, Finance, Marketing, and Management. Proceedings of the Twelfth International Symposium in Economic Theory and Econometrics, 83-110. http://dx.doi.org/10.1017/CBO9780511896682.008

[4] Keen, S. (1995) Finance and Economic Breakdown: Modeling Minsky’s Financial Instability Hypothesis. Journal of Post Keynesian Economics, 17, 607-635.

[5] Bernanke, B.S., Gertler, M. and Gilchrist, S. (1999) The Financial Accelerator in a Quantitative Business Cycle Framework. Handbook of Macroeconomics, 1, 1341-1393. http://dx.doi.org/10.1016/S1574-0048(99)10034-X

[6] Mittnik, S. and Semmler, W. (2013) The Real Consequences of Financial Stress. Journal of Economic Dynamics and Control, 37, 1479-1499. http://dx.doi.org/10.1016/j.jedc.2013.04.014

[7] Adrian, T., Moench, E. and Shin, H.S. (2010) Macro Risk Premium and Intermediary Balance Sheet Quantities. IMF Economic Review, 58, 179-207. http://dx.doi.org/10.1057/imfer.2010.5

[8] Gorton, G.B. (2010) Slapped by the Invisible Hand: The Panic of 2007. Oxford University Press, Oxford.

[9] Geanakoplos, J. (2010) The Leverage Cycle. In: NBER Macroeconomics Annual 2009, Volume 24, University of Chicago Press, Chicago, 1-65. http://dx.doi.org/10.2139/ssrn.1539483

[10] Brunnermeier, M.K. and Sannikov, Y. (2014) A Macroeconomic Model with a Financial Sector. American Economic Review, 104, 379-421. http://dx.doi.org/10.1257/aer.104.2.379

[11] Proaño, C.R., Schoder, C. and Semmler, W. (2014) Financial Stress, Sovereign Debt and Economic Activity in Industrialized Countries: Evidence from Dynamic Threshold Regressions. Journal of International Money and Finance, 45, 17-37. http://dx.doi.org/10.1016/j.jimonfin.2014.02.005

[12] Checherita-Westphal, C., Hughes Hallett, A. and Rother, P. (2014) Fiscal Sustainability Using Growth-Maximizing Debt Targets. Applied Economics, 46, 638-647. http://dx.doi.org/10.1080/00036846.2013.861590

[13] Keen, S. (2013) A Monetary Minsky Model of the Great Moderation and the Great Recession. Journal of Economic Behavior and Organization, 86, 221-235. http://dx.doi.org/10.1016/j.jebo.2011.01.010

[14] Grüne, L., Semmler, W. and Sieveking, M. (2005) Creditworthiness and Thresholds in a Credit Market Model with Multiple Equilibria. Economic Theory, 25, 287-315.http://dx.doi.org/10.1007/s00199-003-0442-8

[15] Greiner, A., Grüne, L. and Semmler, W. (2014) Economic Growth and the Transition from Non-Renewable to Renewable Energy. Environment and Development Economics, 19, 417-439. http://dx.doi.org/10.1017/S1355770X13000491. 